\title{
"Safe and Effective When Used As Directed": The Case of Chronic Use of Opioid Analgesics
}

\author{
Jane C. Ballantyne
}

Published online: 15 September 2012

(C) American College of Medical Toxicology 2012

\begin{abstract}
Opioid analgesics have been used increasingly over the past 20 years for the management of chronic noncancer pain in the USA under the assumption that they were safe and effective when used as directed. The accuracy of that assumption has not been tested against accumulated evidence. The safety of opioids used on a long-term basis has not been tested in clinical trials. Epidemiologic evidence from examinations of such use in the general population indicates that the risk of overdose increases in a doseresponse manner. Such evidence also suggests increased risk of fractures and acute myocardial infarctions among elderly users of opioids for chronic pain. Experimental evidence supports short-term use of opioids, but trials of long-term use for chronic pain have not been conducted. Epidemiologic evidence suggests that long-term use does not result in improvement in function or quality of life while being associated with significant dropout rates and a high prevalence of adverse drug effects. Substantial fractions of patients are not using opioid analgesics as directed, while millions of US residents are using them without a prescription for nonmedical reasons. A prudent treatment approach consistent with the available evidence would be to reserve chronic opioid therapy for serious pain-related problems for which the effectiveness of opioids has been demonstrated and for patients whose use as directed is assured through close monitoring and for whom an explicit, informed calculation has been made that the benefits of opioids outweigh the risks.
\end{abstract}

Keywords Opioid $\cdot$ Poisoning $\cdot$ Safety $\cdot$ Effectiveness

\footnotetext{
J. C. Ballantyne $(\square)$

Department of Anesthesiology and Pain Medicine,

University of Washington,

1959 NE Pacific St., Room BB 1459, Box 356540, Seattle, WA 98195, USA

e-mail: jcb12@u.washington.edu
}

\section{Background}

Historically, concerns about long-term use of opioids to treat chronic pain were related to two factors: fear that chronic use would be associated with an unacceptably high risk of addiction and a belief that neuropathic pain (which accounts for much chronic intractable pain) is not responsive to opioids $[1,2]$. These two factors were embedded in the teaching that persisted throughout most of the twentieth century, i.e., that opioids should be avoided when treating chronic pain. In the 1980s, however, borrowing from their experience in palliative care, a number of physicians began treating chronic non-cancer pain with opioids and subsequently promoted chronic opioid therapy (COT) on the basis of the success they had in their own practices. Beginning slowly in the early 1990s, but accelerating over time, the paradigm for chronic pain treatment shifted toward the acceptance of COT. Now, almost 20 years later, it is time to review the current assumption that opioids are safe and effective when used as directed. Each part of that assumption can now be tested against the real-world experience gained from more permissive use of opioids for treatment of chronic pain in the USA.

\section{Safety}

As opioid prescribing increased during the 1990s, the first sign of a safety issue, unrecognized at the time, was an increase in the rate of drug overdose death by 1995 [3]. Opioid analgesic overdose deaths could not be identified as the cause of the mortality increase until the USA adopted a new coding scheme that separated opioid analgesics from heroin for the first time in 1999 [4]. It then shortly became clear that opioid analgesics were driving the increase (Fig. 1). At about the same time, it became apparent that 


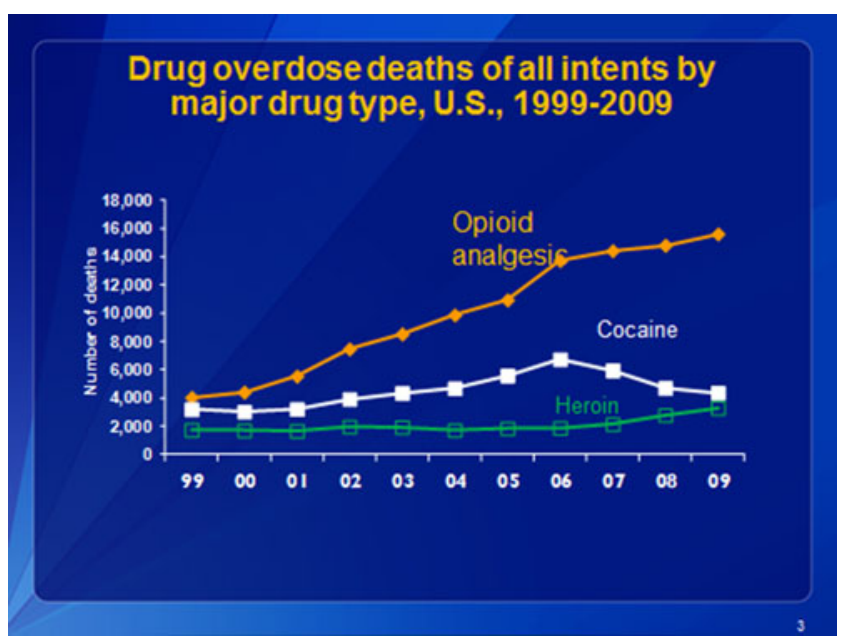

Fig. 1 Drug overdose deaths of all intents by major drug type, US, 1999-2009. (Courtesy of National Vital Statistics System accessed through CDC WONDER query system at http://wonder.cdc.gov/ med.html)

emergency department visits from overdoses of opioids had multiplied [5]. By 2009, well over 100,000 overdose deaths linked to opioid analgesics had occurred. In 2009 alone, more than 15,500 such deaths were recorded. While many people who died had obtained their drugs through diversion, many were also being treated with opioids for pain [6]. Questions quickly arose as to the safety of opioid analgesics.

Assessments of a drug's safety traditionally rely on measurement of the frequency and severity of adverse events in a treated population compared with an untreated population. Ideally, such a comparison is made in a randomized clinical trial (RCT) so that the treated and untreated populations are comparable. However, no placebo-controlled, long-term RCT on the safety of opioids for chronic pain has been conducted $[7,8]$. Data from uncontrolled time series studies are available, but such prospective studies typically exclude patients with a history of addiction or abusive behaviors [8] and therefore do not reflect use in the real world.

Epidemiologic studies observing typical patients treated long term with opioids might be the best available evidence related to the question of safety. Six such studies published since 2010 have found significantly increased risk of overdose associated with the use of opioids, not including opioids obtained from substance abuse treatment programs. In the first study, among patients diagnosed with chronic pain in a health maintenance organization, the risk of opioid overdose, either fatal or nonfatal, was $0.04 \%$ per year when not being treated with opioids and $0.22 \%$ when being treated. The risk increased steadily with daily dosage to $1.79 \%$ per year at 100 or more morphine milligram equivalents (MME) per day [9]. The hazard ratio was $8.87(95 \%$ confidence interval (CI) 3.99-12.48) for $100+\mathrm{MME} /$ day compared with a dosage of $1-<20 \mathrm{MME} /$ day. A study of opioid use in Canada among people receiving public assistance found a risk of fatal opioid overdose of $0.1,0.4$, and $0.5 \%$ per year for those being treated at $\leq 200,201-400$, and $400+$ MME/day, respectively [10]. Other studies have found consistent, strong, dose-response relationships between the use of opioids and the risk of both fatal [11-13] and nonfatal [14] overdose. Increased risk has been seen for those with and without substance abuse disorders and for both cancer pain and other kinds of chronic pain [11]. Nonetheless, even in the lowest-risk groups, researchers could not know whether patients in these studies took their opioids exactly as directed or misused them, e.g., sold them to others, used them with other drugs of abuse, etc. Prescribers, of course, face similar uncertainties.

Four recent studies of older adults have also suggested a substantial increase in serious adverse events other than overdoses among older adults initiating the use of opioid analgesics. Saunders found an incidence of fractures of 10.0/ 100 person years among older $(60+$ years old $)$ people using opioids for chronic pain versus a risk of 3.8/100 person years among nonusers [15]. Solomon found that the incidence of fractures was 10.1/100 person years among Medicare beneficiaries (mean age 80 years) using opioids for arthritis versus $2.6 / 100$ person years in a population matched on propensity scores using nonsteroidal antiinflammatory drugs (NSAIDs). Cardiovascular events such as acute myocardial infarctions occurred at a rate of 12.2/ 100 person years in the opioid group and 7.7/100 person years in the NSAID group. Both differences were statistically significant [16]. Miller studied older adults (65+years old) with arthritis and reported results similar to those of Solomon: fractures occurred at a rate of $12.0 / 100$ person years among those who initiated use of an opioid compared with a rate of $2.5 / 100$ person years among those starting an NSAID (hazard ratio 4.9, 95 \% CI 3.5-6.9). Risk increased steadily with increasing opioid dose and was greatest during the first 2 weeks of use [17]. A fourth study found similar risk increases for falls with use of opioid analgesics [18]. While multiple prescription drugs might have adverse effects on the elderly, the greater fracture risk from opioids should be accompanied by a greater benefit to justify their choice over available alternatives such as NSAIDS.

What risk of adverse events from long-term opioid therapy is unacceptable? A comparison to recent experience with a non-opioid analgesic might provide a benchmark for unacceptable risk. Rofecoxib (Vioxx ${ }^{\circledR}$ ) was introduced as a COX-2 NSAID in the USA in 1999 and heavily marketed for its lower risk of gastrointestinal bleeding when compared with traditional NSAIDs. In 2000, results of an RCT indicated a risk of acute myocardial infarction (AMI) of $0.4 / 100$ person years among people with arthritis treated with rofecoxib compared with $0.1 / 100$ person years risk for patients treated with naproxen, but the difference was 
initially attributed to a cardioprotective effect of naproxen [19]. However, a meta-analysis published in 2001 found an annual AMI risk of $0.7 \%$ among patients receiving rofecoxib compared with $0.5 \%$ among patients on placebo [20]. The use of rofecoxib continued: between 1999 and 2004, 107 million prescriptions of rofecoxib were written in the USA [21]. Three subsequent epidemiologic studies found a two- to fourfold increase in the risk of AMI with the use of rofecoxib at higher dosages compared with no use [21-23]. Merck withdrew rofecoxib from the market in 2004 because of the risk of AMI, despite the fact that rofecoxib significantly reduced the risk of gastrointestinal bleeding compared with NSAIDs in an RCT [24]. The latest analysis has suggested that rofecoxib caused 1,637 AMI deaths each year it was on the market [25].

For both COT and rofecoxib, epidemiologic studies indicate greater risk for adverse events when compared with NSAIDs. Studies of overdose risk from COT have no appropriate comparators since overdoses from alternative analgesics are relatively rare. Comparing risks of injury from falls and overdose with the risk of medical complications such as gastrointestinal bleeding from NSAIDs is difficult. Nonetheless, the story of rofecoxib indicates that pharmacoepidemiologic data should not be discounted in the absence of RCTs. Such data might be the only way to decide on acceptable risk.

\section{Effectiveness}

The studies that can be found in the literature from the late 1980s and early 1990s strongly support the efficacy of longterm opioid therapy [26]. A report by Portenoy and Foley in 1986 can be considered as a seminal article because it was widely cited in support of chronic opioid therapy [27]. These authors reported improvements in pain and function for 38 patients with non-cancer pain diagnoses treated for up to 7 years with moderate doses of opioids. Their findings were mirrored in many other published case series at the time-COT appeared to benefit the patients treated and be associated with low risk [26]. More recently, observational studies have expanded to include open-label continuation studies undertaken as part of the design for the growing number of RCTs being conducted to assess opioid efficacy in chronic pain. For these observational studies, again, useful short-term analgesic efficacy is established, but overall, no conclusions can be reached about COT's ability to improve function or quality of life [28]. What is important to recognize in terms of the observational studies that broadly provide strong support for COT, at least in terms of analgesic efficacy, is that the majority of these studies are conducted for months, not years, and the doses used in the studies fall in the moderate range. The fact that there are only a few outliers in these studies, both in terms of length of treatment and dose $[29,30]$, reflects actual practice where evidence suggests that low- to moderate-dose usage is more common, and high-dose therapy (100+MME) is relatively rare $[31,32]$. An important new finding of the open-label studies is that up to $60 \%$ of patients who start COT abandon the therapy for lack of efficacy or intolerable side effects $[28,33,34]$.

Old and established treatments do not need to be tested for efficacy by RCTs. Morphine, being such, was not tested, and in fact, there was a paucity of RCTs evaluating opioids in chronic pain patients until as late as the 1990s. When Portenoy and Foley published their 1986 observational study, there were virtually none. When RCTs to test opioid efficacy in chronic pain conditions first appeared, they addressed specific questions: were newer formulations superior? and were chronic pain conditions responsive, especially neuropathic pain, which was previously believed to be unresponsive? Not surprisingly, RCTs have tended to focus on just two types of chronic pain: neuropathic and musculoskeletal. Also, these trials are conducted for relatively short periods (generally weeks rather than months); patients are carefully selected (for example, patients with risk of substance use or other mental health disorders are screened out), and doses used are generally low to moderate (up to $100 \mathrm{MME}$ ), with $180 \mathrm{MME}$ being the highest and an outlier [35]. The standard randomized studies can inform us about short-term analgesic efficacy and side effects, but clearly, they cannot inform about long-term efficacy or adverse outcomes that arise when opioids are used for years rather than weeks or months. Since 1990, increasing numbers of published RCTs, systematic reviews, and meta-analyses have assessed COT. Addressing specifically the issue of responsivity of neuropathic pain to opioids, Eisenberg et al. in 2005 found eight trials demonstrating superior analgesic efficacy for up to 28 days [1]. Kalso et al. in 2004 found good short-term analgesic efficacy in both neuropathic and musculoskeletal pain for up to 8 weeks across 11 studies [33]. These studies have gradually disproved the myth that neuropathic pain does not respond to opioids. More recently in 2009, a Cochrane review by Nuesch et al. of opioid treatment of osteoarthritic pain including ten trials found superior analgesic efficacy over the short duration of the trials, no real differences in efficacy between different opioids, but a significant association with adverse effects; again, dropout rates were high [34]. Papaleontiou et al. in 2010 specifically selected articles on older adults, finding 43 (31 RCTs) on patients over 60 years of age [36]. They concluded that COT was associated with reduced pain intensity and improved physical functioning but poorer mental health, at least for short-term therapy.

We have seen consistent support for COT from observational and trial data, but these types of data are limited to 
relatively short-term use in select populations. Biologically, however, dependence on opioids may take years to develop, and dependence may seriously impair opioid effectiveness [37, 38]. Epidemiologic studies may be the only way we can learn about the long-term effects of certain treatments; opioids may be a case in point. Many of our concerns about safety and efficacy are arising from the epidemiologic studies that are now emerging. Epidemiologic data have their own limitations, largely related to their inability to prove causation. In the case of COT, this is particularly troublesome because it is likely that opioid users are sicker than non-opioid users and that higher doses are used by sicker people. As delineated by Bradford-Hill, however, conditions do exist where epidemiologic associations are more likely to be causal, including the strength, consistency, and biological plausibility of the associations [39]. In aggregate, the epidemiologic data on opioids are painting a consistent but very different picture than that produced by observational data and trials with respect to analgesic efficacy, improvements in function, and quality of life.

One of the first studies to raise concern came from Denmark and compared 228 opioid-treated pain patients with 1,678 matched and non-opioid-treated patients [40]. After controlling for both disease and pain severity, opioid usage was significantly associated with worse pain, worse selfreported health, lower levels of activity and employment, higher healthcare utilization, and poorer quality of life. Subsequent epidemiologic studies report similar findings $[41,42]$. A large body of literature now exists, demonstrating low levels of return to work for injured workers treated with opioids relative to those not receiving opioids [43-47]. Evidence is accumulating that patients treated with opioids who remain on the treatment for more than 90 days are likely to dose-escalate and are unlikely to discontinue the therapy [48, 49]. This in itself speaks to the issue that the neuroadaptations that arise during long-term opioid therapy reduce analgesic efficacy while also making it hard for individuals to discontinue the treatment despite low efficacy and safety [38]. Perhaps most concerning is the accumulating evidence that the patients who stay on opioids and reach the high dose levels, now proving to be ineffective and unsafe, tend to be exactly those individuals we know are likely to spiral out of control, namely those with risk factors for mental health and substance use disorders [14, 31, 49-56]. In short, the epidemiologic data are highlighting that for many of the individuals who continue with COT (and a majority do not), treatment failure and loss of control may be signaled by dose escalation and prolonged use ( $>90$ days) [49], while there is some indication that lowdose and intermittent opioid users may be the patients that do not develop control issues $[57,58]$ and derive the greatest benefit $[31,35]$.

\section{Use As Directed}

The safety and effectiveness of opioid analgesics cannot be predicted if they are not used as directed. It is therefore worth inquiring how much of their long-term use in the USA today is "as directed". Several lines of evidence shed light on how opioids are used long-term by patients: responses of patients when asked how they used their drugs, observations of patients engaged in aberrant drug-related behaviors, and toxicology testing for indications that patients were not using their drugs in a manner consistent with the prescribed regimen. Not using as directed is described in other contexts as being noncompliant or, less prejudicially, as being nonadherent [59].

Nonadherence can include taking too much of a medication, affecting safety, and taking too little of it, reducing effectiveness. Studies that have quantified adherence to long-term medication find that roughly $50 \%$ of patients are nonadherent to treatment for a variety of conditions [60]. Adherence might be expected to be somewhat different for opioids than for drugs for other chronic conditions because opioids are addictive, potentially making overuse more likely, and because failure to use the drugs might result in an increase in pain. On the other hand, pain, unlike problems such as hypertension, might be intermittent. Therefore, it might be appropriate to use less than directed as long as leftover drugs are not diverted to other people.

Patient self-reports of how they use their prescribed opioid analgesics are subject to underreporting of use other than as directed [61], perhaps because of fear of repercussions. Nonetheless, reporting overuse is more common than reporting underuse. In one HMO, a survey of patients using opioids for chronic non-cancer pain found that $46 \%$ reported using opioids for non-pain symptoms, $42 \%$ reported nonadherence such as increasing the dose on their own, and $16 \%$ reported drug-sharing behaviors [62]. In a telephone survey in Utah, $3.2 \%$ of patients prescribed with opioids admitted to using their opioid medication more frequently or in higher doses than prescribed, and $72.0 \%$ reported that they had leftover medication [63]. Most opioid prescriptions in this study were for acute pain, however, and might have been prescribed on an as-needed basis. Among secondary school students in Michigan, $20.1 \%$ reported nonprescribed use of their own opioid analgesic prescriptions, primarily taking more than prescribed [64].

The behavior patterns of patients being prescribed with opioids serve as indirect measures for failure to use opioids as directed. Aberrant drug-related behaviors (ADRBs) among such patients have been quantified. ADRB include behaviors such as nonmedical routes of administration such as injection, unsanctioned dosing or dose escalation, and selling their drugs [65]. A structured, evidence-based review found that on average, $11.5 \%$ of patients on chronic opioid 
analgesic therapy exhibited ADRB [66]. Other researchers have used DSM-IV criteria to quantify opioid dependence among patients in a general medical population using opioids long-term, finding that $26 \%$ met the criteria for current and $36 \%$ for lifetime opioid dependence $[67,68]$. Similarly, the prevalence of an indicator of possible current opioid misuse by patients on COT was $24 \%$, based on claims in a large commercial insurance database [69].

Perhaps the most sensitive measure of whether patients are using their opioids as directed is toxicologic testing. Data from clinical laboratories are available for urine drug tests conducted on chronic pain patients being monitored for nonadherence. A national laboratory dataset for nearly one million tests conducted during 2006-2008 revealed that $38 \%$ of patients had no detectable level of their prescribed opioid analgesic, $15 \%$ had a drug level lower than expected, and $27 \%$ had a drug level higher than expected [70]. These data are subject to selection bias because prescribers might have preferentially tested patients whom they suspected of nonadherence. Other studies have found high rates of problematic drug test results in settings where all patients were routinely tested. For example, among all patients receiving COT in one pain clinic, $29 \%$ had "positive" urine toxicology [61]. In another clinic, $45 \%$ of patients were found to have abnormal urine screens [71]. However, patients seen in specialized pain clinics might also be more likely to have substance abuse problems. Unfortunately, no random sample of urine tests of patients taking opioids long term is available, but nonadherence appears common in many subpopulations of users.

Another approach to measuring adherence is to quantify the different types of users of opioids long term within the US population as a whole rather than within patient populations. In the 2010 National Survey of Drug Use and Health (NSDUH), $4.8 \%$ of the US population 12 or more years old, 12.2 million people, reported nonmedical use of prescription opioids in the past year (i.e., use without a prescription or for the feeling they cause) [72]. Long-term nonmedical use, for example, for 30 or more days in the past year, was reported by nearly $2 \%$ (4.6 million) of the US population in the NSDUH [73]. By comparison, an estimated 10 million US adults were on COT in 2005, based on extrapolation from the medical records of a health maintenance organization [74]. Some of these patients might have also met the definition of nonmedical use if they were using their prescribed opioids for the feeling they caused. Some might have given their drugs to others. Based on the substantial number of nonmedical users, on average, some proportion of each opioid analgesic prescription will be employed for nonmedical use either by patients or by those who obtain their drugs.

These multiple sources of evidence about how opioids are used once prescribed suggest that, while people will admit to researchers that they use these drugs inappropriately, they are unlikely to admit such behavior to the people who prescribe the drugs. As a result, prescribers have limited assurance that "use as directed" will occur.

\section{Conclusions}

Evidence that questions the dominant paradigm supporting COT is accumulating. Opioid analgesics are being used on a long-term basis for chronic pain in the USA today under assumptions of safety, effectiveness, and use as directed with limited empiric support. Such widespread use is inarguably resulting in misuse and diversion of substantial amounts of drugs, behaviors that drive increasing rates of overdoses and other adverse health outcomes. A prudent treatment approach consistent with the latest evidence would be to reserve chronic opioid therapy for serious pain-related problems for which the effectiveness of opioids has been demonstrated and for patients whose use as directed can be assured through monitoring and for whom an explicit, informed calculation has been made that benefits outweigh risks.

\section{References}

1. Eisenberg E, McNicol ED, Carr DB (2005) Efficacy and safety of opioid agonists in the treatment of neuropathic pain of nonmalignant origin: systematic review and meta-analysis of randomized controlled trials. JAMA 293:3043-3052

2. Ng L (1981) New approaches to treatment of chronic pain: a review of multidisciplinary pain clinics and pain centers. NIDA Res Monogr 36

3. Fingerhut LA, Cox CS (1998) Poisoning mortality, 1985-1995. Public Health Rep 113:218-233

4. Paulozzi LJ, Budnitz DS, Xi Y (2006) Increasing deaths from opioid analgesics in the United States. Pharmacoepidemiol Drug Saf 15:618-627

5. Substance Abuse and Mental Health Services Administration (2004) Narcotic analgesics, 2002 update. Substance Abuse and Mental Health Services Administration, Center for Behavioral Health Statistics and Quality, Rockville

6. Hall AJ, Logan JE, Toblin RL, Kaplan JA, Kraner JC, Bixler D, Crosby AE (2008) Patterns of abuse among unintentional pharmaceutical overdose fatalities. JAMA 300:2613-2620

7. Furlan A, Chaparro L, Irvin E, Mailis-Gagnon A (2011) A comparison between enriched and nonenriched enrollment randomized withdrawal trials of opioids for chronic noncancer pain. Pain Res Manag 16:337-351

8. Noble M, Tregear S, Treadwell J, Shchoelles K (2008) Long-term opioid therapy for chronic noncancer pain: a systematic review and meta-analysis of efficacy and safety. J Pain Symptom Manage 35:214-228

9. Dunn KM, Saunders KW, Rutter CM, Banta-Green CJ, Merrill JO, Sullivan MD, Weisner CM (2010) Opioid prescriptions for chronic pain and overdose. Ann Intern Med 152:85-92

10. Gomes T, Juurlink DN, Dhalla IA, Mailis-Gagnon A, Paterson JM, Mamdani MM (2011) Trends in opioid use and dosing among socio-economically disadvantaged patients. Open Med 5:E13-E22 
11. Bohnert AS, Valenstein M, Bair MJ, Ganoczy D, McCarthy JF, Ilgen MA, Blow FC (2011) Association between opioid prescribing patterns and opioid overdose-related deaths. JAMA 305:1315-1321

12. Gomes T, Mamdani M, Dhalla I, Paterson J, Juurlink D (2011) Opioid dose and drug-related mortality in patients with nonmalignant pain. Arch Intern Med 17:686-691

13. Paulozzi LJ, Kilbourne E, Shah N, Nolte K, Desai H, Landen M, Harvey W, Loring L (2012) A history of being prescribed controlled substances and risk of drug overdose death. Pain Med 13:87-95

14. Braden JB, Russo J, Fan M-Y, Edlund MJ, Martin BC, DeVries A, Sullivan MD (2010) Emergency department visits among recipients of chronic opioid therapy. Arch Intern Med 170:1425-1432

15. Saunders K, Dunn K, Merrill J, Sullivan M, Weisner C, Braden J, Psaty B, Von Korff M (2009) Relationship of opioid use and dosage levels to fractures in older chronic pain patients. J Gen Intern Med 25:310-315

16. Solomon D, Rassen J, Glynn R, Lee J, Levin R, Schneeweiss S (2010) The comparative safety of analgesics in older adults with arthritis. Arch Intern Med 170:1968-1978

17. Miller M, Sturmer T, Azrael D, Levin R, Solomon D (2011) Opioid analgesics and the risk of fractures in older adults with arthritis. J Am Geriatr Soc 59:430-438

18. Rolita L, Spegman A, Cronstein B (2011) Unintended consequences: increased prescription of narcotic analgesics for $\mathrm{OA}$ in the elderly is associated with increased falls and fractures in the postVioxx era. ACR/ARHP Annual Scientific Meeting. American College of Rheumatology, Chicago

19. Bombardier C, Laine L, Reicin A, Shapiro D, Burgos-Vargas R, Davis B, Day R, Ferraz M, Hawkey J, Hochberg M, Kvien T, Schnitzer T (2000) Comparison of upper gastrointestinal toxicity of rofecoxib and naproxen in patients with rheumatoid arthritis. NEJM 343:1520-1528

20. Mukherjee D, Nissen S, Topol E (2001) Risk of cardiovascular events associated with selective COX-2 inhibitors. JAMA 286:954-959

21. Graham D, Campen D, Hui R, Spence M, Cheetham C, Levy G, Shoor S, Ray W (2005) Risk of acute myocardial infarction and sudden cardiac death in patients treated with cyclo-oxygenase 2 selective and non-selective non-steroidal anti-inflammatory drugs: nested case-control study. Lancet 365:475-481

22. Ray W, Stein C, Daugherty J, Hall K, Arbogast P, Griffin M (2002) COX-2 selective non-steroidal anti-inflammatory drugs and risk of serious coronary heart disease. Lancet 360:1071-1073

23. Solomon D, Schneeweiss S, Glynn R, Kiyota Y, Levin R, Mogun H, Avorn J (2004) Relationship between selective cyclooxygenase2 inhibitors and acute myocardial infarction in older adults. Circulation 109:2068-2073

24. Topol E (2004) Failing the public health-rofecoxib, Merck, and the FDA. NEJM 351:1707-1709

25. Vaithianathan R, Hockey P, Moore T, Bates D (2009) Iatrogenic effects of COX-2 inhibitors in the US population. Drug Saf 32:335-343

26. Ballantyne JC, Shin NS (2008) Efficacy of opioids for chronic pain: a review of the evidence. Clin J Pain 24:469-478

27. Portenoy RK, Foley KM (1986) Chronic use of opioid analgesics in non-malignant pain: report of 38 cases. Pain 25:171-186

28. Noble M, Treadwell JR, Tregear SJ, Coates VH, Wiffen PJ, Akafomo C, Schoelles KM (2010) Long-term opioid management for chronic noncancer pain. Cochrane Database Syst Rev CD006605

29. Tennant FS, Robinson D, Sagherian AS, Seecof R (1988) Chronic opioid treatment of intractable non-malignant pain. NIDA Res Monogr 81:174-780

30. Zenz M, Strumpf M, Tryba M (1992) Long-term opioid therapy in patients with chronic nonmalignant pain. J Pain Symptom Manage 7:69-77
31. Morasco BJ, Duckart JP, Carr TP, Deyo RA, Dobscha SK (2010) Clinical characteristics of veterans prescribed high doses of opioid medications for chronic non-cancer pain. Pain 151:625-632

32. Von Korff M (2012) The epidemiology of use of opioids for chronic pain. In Assessment of Analgesic Treatment of Chronic Pain: A Scientific Workshop. US Food and Drug Administration, Bethesda

33. Kalso E, Edwards JE, Moore RA, McQuay HJ (2004) Opioids in chronic non-cancer pain: systematic review of efficacy and safety. Pain 112:372-380

34. Nuesch E, Rutjes AW, Husni E, Welch V, Juni P (2009) Oral or transdermal opioids for osteoarthritis of the knee or hip. Cochrane Database Syst Rev CD003115

35. Ballantyne JC, Mao J (2003) Opioid therapy for chronic pain. N Engl J Med 349:1943-1953

36. Papaleontiou M, Henderson CR Jr, Turner BJ, Moore AA, Olkhovskaya Y, Amanfo L, Reid MC (2010) Outcomes associated with opioid use in the treatment of chronic noncancer pain in older adults: a systematic review and meta-analysis. J Am Geriatr Soc 58:1353-1369

37. Ballantyne JC, LaForge SL (2007) Opioid dependence and addiction in opioid treated pain patients. Pain 129:235-255

38. Ballantyne JC, Sullivan MD, Kolody A (2012) Opioid dependence vs addiction: a distinction without a difference? Arch Int Med $13: 1-2$

39. Hill AB (1965) The environment and disease: association or causation? Proc R Soc Med 58:295-300

40. Eriksen J, Sjogren P, Bruera E, Ekholm O, Rasmussen NK (2006) Critical issues on opioids in chronic non-cancer pain. An epidemiological study. Pain 125:172-179

41. Dillie KS, Fleming MF, Mundt MP, French MT (2008) Quality of life associated with daily opioid therapy in a primary care chronic pain sample. J Am Board Fam Med 21:108-117

42. Sjogren P, Gronbaek M, Peuckmann V, Ekholm O (2010) A population-based cohort study on chronic pain: the role of opioids. Clin J Pain 26:763-769

43. Franklin GM, Mai J, Wickizer T, Turner JA, Fulton-Kehoe D, Grant L (2005) Opioid dosing trends and mortality in Washington State workers' compensation, 1996-2002. Am J Ind Med 48:91-99

44. Franklin GM, Stover BD, Turner JA, Fulton-Kehoe D, Wickizer TM (2008) Early opioid prescription and subsequent disability among workers with back injuries: the Disability Risk Identification Study Cohort. Spine (Phila Pa 1976) 33:199-204

45. Gross DP, Stephens B, Bhambhani Y, Haykowsky M, Bostick GP, Rashiq S (2009) Opioid prescriptions in Canadian workers' compensation claimants: prescription trends and associations between early prescription and future recovery. Spine (Phila $\mathrm{Pa}$ 1976) 34:525-531

46. Stover BD, Turner JA, Franklin G, Gluck JV, Fulton-Kehoe D, Sheppard L, Wickizer TM, Kaufman J, Egan K (2006) Factors associated with early opioid prescription among workers with low back injuries. J Pain 7:718-725

47. Volinn E, Fargo JD, Fine PG (2009) Opioid therapy for nonspecific low back pain and the outcome of chronic work loss. Pain 142:194-201

48. Franklin GM, Rahman EA, Turner JA, Daniell WE, Fulton-Kehoe D (2009) Opioid use for chronic low back pain: a prospective, population-based study among injured workers in Washington state, 2002-2005. Clin J Pain 25:743-751

49. Martin BC, Fan MY, Edlund MJ, Devries A, Braden JB, Sullivan MD (2011) Long-term chronic opioid therapy discontinuation rates from the TROUP study. J Gen Intern Med 26:1450-1457

50. Edlund MJ, Martin BC, Fan MY, Devries A, Braden JB, Sullivan MD (2010) Risks for opioid abuse and dependence among recipients of chronic opioid therapy: results from the TROUP study. Drug Alcohol Depend 112:90-98 
51. Phifer J, Skelton K, Weiss T, Schwartz AC, Wingo A, Gillespie CF, Sands LA, Sayyar S, Bradley B, Jovanovic T, Ressler KJ (2011) Pain symptomatology and pain medication use in civilian PTSD. Pain 152:2233-2240

52. Richardson LP, Russo JE, Katon W, McCarty CA, Devries A, Edlund MJ, Martin BC, Sullivan M (2012) Mental health disorders and long-term opioid use among adolescents and young adults with chronic pain. J Adolesc Health 50:553-558

53. Schwartz AC, Bradley R, Penza KM, Sexton M, Jay D, Haggard PJ, Garlow SJ, Ressler KJ (2006) Pain medication use among patients with posttraumatic stress disorder. Psychosomatics 47:136-142

54. Seal KH, Shi Y, Cohen G, Maguen S, Krebs EE, Neylan TC (2012) Association of mental health disorders with prescription opioids and high-risk opioid use in US veterans of Iraq and Afghanistan. JAMA 307:940-947

55. Sullivan MD, Edlund MJ, Zhang L, Unutzer J, Wells KB (2006) Association between mental health disorders, problem drug use, and regular prescription opioid use. Arch Intern Med 166:20872093

56. Weisner CM, Campbell CI, Ray GT, Saunders K, Merrill JO, BantaGreen C, Sullivan MD, Silverberg MJ, Mertens JR, Boudreau D, Von Korff M (2009) Trends in prescribed opioid therapy for non-cancer pain for individuals with prior substance use disorders. Pain 145:287-293

57. Ballantyne JC (2011) Opioids around the clock? Pain 152:12211222

58. Von Korff MR, Merrill JO, Rutter CM, Sullivan M, Campbell CI, Weisner C (2011) Time-scheduled versus pain-contingent opioid dosing in chronic opioid therapy. Pain 152:1256-1262

59. Larance B, Degenhardt L, Lintzeris N, Winstock A, Mattick R (2011) Definitions related to the use of pharmaceutical opioids: extramedical use, diversion, non-adherence and aberrant medication-related behaviours. Drug Alcohol Rev 30:236-245

60. Morris LS, Schulz R (1992) Patient compliance-an overview. J Clin Pharm Ther 17:283-295

61. Katz NP, Sherburne S, Beach M, Rose RJ, Vielguth J, Bradley J, Ganciullo GJ (2003) Behavioral monitoring and urine toxicology testing in patients receiving long-term opioid therapy. Anesth Analg 97:1097-1102

62. Grattan A, Sullivan M, Saunders K, Campbell C, VonKorff M (2012) Depression and prescription opioid misuse among chronic opioid therapy recipients with no history of substance abuse. Ann Fam Med 10:304-311
63. Porucznik C, Sauer B, Johnson E, Crook J, Wrathall J, Anderson J, Rolfs R (2010) Adult use of prescription opioid pain medicationsUtah, 2008. MMWR 59:153-157

64. McCabe S, West B, Cranford J, Ross-Durow P, Young A, Teter C, Boyd C (2011) Medical misuse of controlled medications among adolescents. Arch Pediatr Adolesc Med 165:729-735

65. Passik S, Kirsh K, Whitcomb L, Dickerson P, Theobald D (2002) Pain clinicians' rankings of aberrant drug-taking behaviors. J Pain Palliat Care Pharm 16:39-49

66. Fishbain DA, Cole B, Lewis J, Rosomoff HL, Rosomoff RS (2008) What percentage of chronic nonmalignant pain patients exposed to chronic opioid analgesic therapy develop abuse/addiction and/or aberrant drug-related behaviors? A structured evidence-based review. Pain Med 9:444-459

67. Boscarino J, Rukstalis M, Hoffman S, Han J, Erlich P, Gerhard G, Stewart W (2010) Risk factors for drug dependence among outpatients on opioid therapy in a large US health-care system. Addiction 105:1776-1782

68. Boscarino J, Rukstalis M, Hoffman R, Han J, Erlich P, Ross S, Gerhard G, Stewart W (2011) Prevalence of prescription opioiduse disorder among chronic pain patients: comparison of the DSM5 vs. DSM-4 diagnostic criteria. J Addict Dis 30:185-194

69. Sullivan M, Edlund MJ, Fan M, DeVries A, Braden JB, Martin BC (2010) Risks for possible and probable opioid misuse among recipients of chronic opioid therapy in commercial and medicaid insurance plans: the TROUP study. Pain 150:332-339

70. Couto JE, Romeny M, Leider H, Sharma S, Goldfarb N (2009) High rates of inappropriate drug use in the chronic pain population. Popul Health Manag 12:185-190

71. Michna E, Jamison RN, Pham L, Ross EL, Janfaza D, Nedeljkovic SS (2007) Urine toxicology screening among chronic pain patients on opioid therapy: frequency and predictability of abnormal findings. Clin J Pain 23:173-179

72. Substance Abuse and Mental Health Services Administration (2011) Results from the 2010 National Survey on Drug Use and Health: detailed tables. NSDUH Series H-41. Substance Abuse and Mental Health Services Administration, Center for Behavioral Health Statistics and Quality, Rockville

73. Jones C (2012) Frequency of prescription pain reliever nonmedical use: 2002-2003 and 2009-2010. Arch Intern Med

74. Boudreau D, Von Korff M, Rutter CM, Saunders K, Ray GT, Sullivan MD, Campbell CI (2009) Trends in long-term opioid therapy for chronic non-cancer pain. Pharmacoepidemiol Drug Saf 18:1166-1175 